may have been dulled by a century or so underground, is more readily convinced of molecular drive's significance than I am. Having scripted Darwin's endorsement of his theory, Dover then settles down to enjoy his new role as Darwin's speech-writer. Responding to a lengthy Dover diatribe against Richard Dawkins, whose "selfish genery is genetically misconceived, operationally incoherent and seductively dangerous", Darwin reports that he will conscientiously hunt up Dawkins's books in a library: "I hope they are not filed under 'Science'!".

Dear Mr Darwin, however, is not confined to molecular drive and having Darwin say nasty things about Richard Dawkins. Dover writes at length on recent advances in developmental genetics, and adds his voice to those objecting to evolutionary psychology's insistence on attributing every quirk of human behaviour to the action of natural selection. Given that evolutionary psychology is an implicitly genetic theory (a trait must have a genetic basis to be subject to natural selection), it is interesting to note that many of its most persistent critics are geneticists.

Dear Mr Darwin is an engaging tour of Dover's passions, even if some are announced with more fanfare than they merit. Let us hope, however, that Dover's communications with Darwin do not create a literary fad based on the harassment of dead scientists. The thought of Linnaeus being badgered by manic modern cladists is alarming. On receiving one of Wallace's spiritualist publications, $\mathrm{T}$. $\mathrm{H}$. Huxley replied, "I never cared for gossip in my life, and disembodied gossip, such as these worthy ghosts supply their friends with, is not more interesting to me than any other."

A. J. Berry is at the Museum of Comparative Zoology Labs, 26 Oxford Street, Cambridge, Massachusetts 02138, USA.

\section{On being human}

\section{The Cultural Origins of Human \\ Cognition}

by Michael Tomasello

Harvard University Press: 1999. 248 pp.

$\$ 29.95, £ 18.50$

\section{Andrew Whiten}

Human language and thought elevate us mentally to a grade far removed from anything known in other animals. Yet it has happened in just a twinkling of evolutionary time. Less than six million years separate us from the non-human, non-verbal ancestor we share with chimpanzees. So, suggests Michael Tomasello, we are faced with a puzzle: how could human minds vault this high so quickly? The question becomes more acute if one acknowledges little sign of any accomplishment beyond basic ape mentality until two million years ago or even less. Tomasello's solution - given how far he wants to push the idea - is a radical one. Depending on the reader, I suspect it will elicit excitement, irritation or incredulity. These different reactions may be more or less appropriate according to the evolutionary timescale Tomasello truly aspires to address.

The key proposition is that there was just one critical step in biological evolution which transformed our ancestors' capacity to sustain culture. A new 'ratchet' effect arose, in which cultural advances were built upon progressively in a way not seen in the social traditions of other animals. Human cognition would thenceforth become increasingly complex and differentiated, eventually achieving modern levels of sophistication without need of further biological change.

To see how radical a proposition this is, consider the case of language. Tomasello is arguing that the structures of our highly elaborated language capacities today have nothing to do with the evolution of a dedicated and, in some views, highly structured language instinct (he gives short shrift to the idea of innate mental modules, of any kind). Instead, he proposes that syntax and all the other complex aspects of human language have simply been built up over the generations, by cumulative, ratcheted, cultural evolution. The biological substrate did not need to change. What makes such a scenario plausible, according to Tomasello, is evidence that, quite early on, the human child demonstrates a capacity to translate between the perspectives of self and other that goes beyond anything seen in apes. Perceiving others as intentional agents, in particular, permits the child to become the kind of 'imitation machine' needed to participate in the powerful ratchet effect.

Tomasello's ambitious thesis requires accounts of changes on three very different timescales; evolutionary, historical and ontogenetic. To this task he brings almost unrivalled authority, based on an influential suite of both comparative and developmental studies; he cites more than 40 observational and experimental studies conducted by his group on monkeys, apes and children. These studies, mostly conducted in the 1990s, cover an impressive array of socio-cognitive capacities, including imitation, joint attention, theory of mind and language acquisition.

This substantial empirical base is coupled with a sophisticated grasp of the theoretical issues at stake, particularly when it comes to Tomasello's prime area of expertise, the development of language. Written with refreshing simplicity and directness, the product is a slim volume that nevertheless packs in a richly articulated and challenging model of mind, backed by a wealth of pithily summarized comparative and developmental studies.

At least two-thirds of the book is devoted to tracing the origins and development of components of cultural learning in children, with a particular emphasis on language. This is a masterly survey, covering pre-linguistic scaffolding for language, the acquisition of symbol and syntax use, discourse and the implications of internalization for other aspects of cognition.

Certain features of Tomasello's thesis are less compelling. He considers the possibility that the vital change may have happened two or even six million years ago. But his argument appears to neglect enormous changes in the brain, which has tripled in size since six million years ago and roughly doubled in the past two million. It seems more likely that whatever elaboration of social and cultural practices occurred in this period, it was underwritten by equally massive and rapidly driven neural changes.

A predominant role for cultural change becomes more likely in the context of the past quarter of a million years of Homo sapiens' existence. If the greater part of existing language structure arose over this period, the idea that this happened through cultural learning and ratcheting processes still constitutes a major challenge to those who argue for innate language systems. Tomasello notes that the main diversification of the Romance languages occurred in a few hundred years; so why could not cultural processes of syntacticization turn an embryonic language into a vastly more complex one over hundreds of thousands of years?

A further doubt is whether Tomasello has correctly identified the critical cognitive step that elevated our ancestors' social sophistication over existing anthropoid psychology. His conclusion is largely founded on experimental findings in captive apes far removed from the rich inputs of their natural environments. Field researchers tend to perceive more advanced cultural processes at work, although these perceptions are difficult to substantiate without experimental controls. Accordingly, we are at something of an impasse on this question. Tomasello's thesis probably depends less than he implies on the exact difference between chimpanzee and human cultural propensity, especially if the thesis gets its main application in the recent rise of Homo sapiens.

Nevertheless, students of primate behaviour are one of several groups who should read this important book. It spells out forcefully what appears to make human development so distinctive, and does so from the perspective of an expert in language acquisition who has also devoted much time to comparative work with apes. It is strong medicine for 
anybody in danger of romanticizing the similarity of ape to child. Developmental psychologists will find here a well-articulated account of the ontogeny of cultural learning, which challenges alternative accounts from the vantage point of extensive research. The book should also be a thought-provoking read for cognitive psychologists, many of whom seem to disregard social and cultural processes. Of course, we have 'cultural psychology', but that is about cultural differences. Tomasello is instead talking about universals, an aspiration of most cognitive psychology. If he is even half-right, the field suffers a serious omission indeed.

Andrew Whiten is at the School of Psychology,

University of St Andrews, St Andrews,

Fife KY16 9JU, UK.

\section{The sequence of words}

Genes, Peoples, and Languages

by Luigi Luca Cavalli-Sforza

Farrar, Straus \& Giroux: 2000. 216 pp. \$24

\section{Patrick V. Kirch}

In the early twentieth century, a uniquely American version of anthropology emerged under the direction of prominent scholars such as Franz Boas, Alfred Kroeber and Edward Sapir. What set this school apart from its European counterparts was its efforts to construct a scientific approach to deep-time human history, and the catholic inclusion of evidence from ethnography, archaeology, linguistics and human biology (then called physical anthropology). Today, tensions within anthropology threaten to explode this model of a 'holistic' approach to the study of human cultures. Luigi CavalliSforza, a geneticist whose research has depended on close collaboration with archaeologists and historical linguists, gives us ample reason to celebrate anew this holistic vision of anthropology.

For several decades, Cavalli-Sforza and his colleagues have pursued a variety of research projects involving not only the mapping of human genetic variation, but also the correlation of geographic patterns of variation with patterns of language distribution, and with archaeological evidence for ancient population movements. The underlying theme integrating these disparate studies traces the biological and cultural evolution of modern Homo sapiens throughout the past 100,000 years.

Over the course of Cavalli-Sforza's career, the methods for studying genetic variation have themselves been radically transformed, from the relatively crude mapping of $\mathrm{ABO}$ blood groups, to the sequencing of DNA, and even the recovery and sequencing of ancient

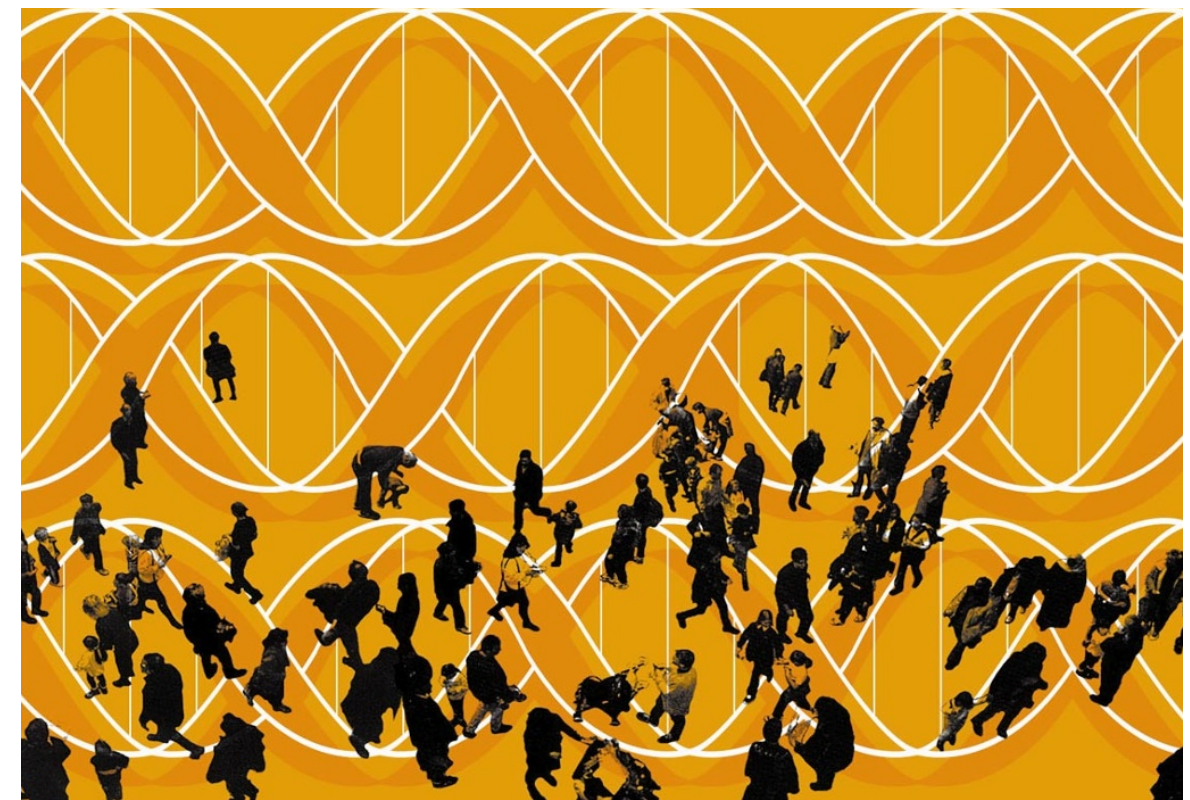

DNA itself. Genes, Peoples, and Languages tells the story of this research odyssey in a style that is highly accessible to intelligent readers from any background, without presuming prior grounding in genetics, statistics or, for that matter, linguistics and archaeology.

In his effort to make his research methods transparent to those without a background in human genetics, however, Cavalli-Sforza ends up devoting much of the first half of his book to a kind of primer in genetics, evolutionary trees and multivariate statistics. This may deter some readers, for the fascinating problems of deep-time human history do not begin to emerge until the fourth chapter. But for those who persist - or simply skip ahead — the intellectual rewards are ample.

In the chapter "Technological revolutions and gene geography", Cavalli-Sforza tackles one of the great problems of historical anthropology: the expansion of modern humans out of Africa, and subsequent diasporas that correlated with major periods of demographic growth. Here he draws on his work with archaeologist Albert Ammerman in demonstrating a major populationexpansion-driven (as opposed to strictly cultural) diffusion from the Near East into Europe, associated with the spread of agricultural peoples. But while the genetic landscape of modern Europe still bears the signature of this major diaspora, other 'streams of gene diffusion' are also evident in statistical patterns of gene distribution, including an expansion from the region north of the Black Sea. This appears to have been associated with the expansion of pastoral nomads who originally domesticated the horse.

Although he dwells at greatest length on Europe, Cavalli-Sforza also discusses evidence for several other major diasporas, including the expansion of Bantu languagespeaking groups in sub-Saharan Africa, and the remarkable dispersal of the Austronesian- language speakers. This latter dispersal would ultimately result in the human colonization of the most remote Pacific islands, including Easter Island and Hawaii.

There are, of course, always pitfalls in multidisciplinary research waiting to entrap unwary scientists stepping beyond the familiar terrain of their own discipline. Writing on language, Cavalli-Sforza is liable to raise some hackles, for not all of his claims fall within what is currently accepted by mainstream historical linguists or prehistorians. This derives, in part, from Cavalli-Sforza's desire to have a 'big picture' classification, or family tree, of world languages, which can then be correlated with his genetic tree of human populations. Unfortunately, the classic methods of historical linguists have serious limitations once one attempts to move back in time to a level deeper than that of major language families. Cavalli-Sforza thus relies heavily on the work of linguists Joseph Greenberg and Merritt Ruhlen, especially the latter's highly controversial 'super-family' classification.

For example, in the key diagram comparing genetic and linguistic trees, CavalliSforza identifies a 'Melanesian' population, and groups it genetically most closely with 'Polynesians' and 'Micronesians', and more distantly with a 'New Guinean' population. Linguistically, the Melanesians and New Guineans are depicted as linked together in an 'Indo-Pacific' family, while the Polynesians and Micronesians are identified as part of the large 'Austronesian' language family.

However, the very concept of a discrete 'Melanesian' population was rejected many years ago, and the notion of an 'Indo-Pacific'language family was similarly abandoned. Rather, the people who occupy the islands of Melanesia (excluding New Guinea) display tremendous genetic variation. This is the result of a specific and complex history of 